\title{
Brief report: marital status and alcohol consumption behaviours
}

Wenbin Liang $^{1^{*}}$ MBBS, MPH, PhD, Tanya Chikritzhs ${ }^{1} \mathrm{PhD}$

${ }^{1}$ National Drug Research Institute, Curtin University of Technology, Perth, Western Australia, Australia

${ }^{*}$ Corresponding author:

Both authors have contributed significantly to the research and the manuscript. The content of the manuscript has been proved by the authors. The authors declare that the submitted material has not been published and is not under consideration for publication elsewhere.

The authors declare no conflicts of interest

\section{Correspondence:}

Wenbin Liang

National Drug Research Institute, Curtin University of Technology, GPO Box U1987, Perth WA 6845 Australia

Phone: +61 $892661617 \quad$ Fax: +61 892661611

Email: w.liang@curtin.edu.au 


\begin{abstract}
Introduction and Aims: Divorced people have been found to be more likely to consume alcohol at higher levels than those who are married, with the association varying somewhat by country. However, the effect that remaining unmarried has on alcohol consumption is less clear. This study investigated the association between marital status and alcohol consumption among young and middle-aged Australian adults. Methods: Using a cross-sectional study design, the association between marital status and alcohol consumption behaviour was assessed using data from the Australian 2007 National Drug Strategy Household Survey. Results: Young and middle-aged people, who were never married, divorced or separated were more likely to consume alcohol at levels associated with increased risk for both long-term and short-term harm when compared to married people. Discussion: It may be possible that mental health status is one of the factors mediating the association between marital status and alcohol consumption. Conclusions: Being never married, divorced or separated was a strong indicator of hazardous alcohol consumption behaviours. The marital status of young and middle-aged people might serve as a useful screening tool for health professionals wishing to identify patients at elevated risk of alcohol-related problems.
\end{abstract}

Key words: Alcohol, Mental health, Harm reduction, Family 


\section{Brief report: marital status and alcohol consumption behaviours}

\section{INTRODUCTION}

\section{$\underline{\text { METHOD }}$ \\ DISCUSSION \\ $\underline{\text { CONCLUSION }}$}

The Authors should confirm that: the material has not been published elsewhere; the paper is not currently being considered for publication elsewhere. The two authors have been personally and substantially involved in the work leading to the paper, and will hold themselves jointly and individually responsible for its content. No financial funding to be reported. 


\section{INTRODUCTION}

Alcohol consumption is a contributing causal factor for various long-term (chronic) and short-term (acute) harms (WHO, 2000). The identification of modifiable factors which influence alcohol consumption levels and other risk factors indirectly related to alcohol misuse might assist in detecting people at heightened risk of alcohol misuse and the subject is therefore of research interest.

According to the fourth Household, Income and Labour Dynamics in Australia (HILDA) Survey, slightly more than $60 \%$ of the $15+$ yrs Australian population were legally or de facto married in 2006 and 25\% had never been married (Wilkins, Warren, \& Hahn, 2009). People who are divorced consume alcohol at higher levels than those who are married, although the association varies among countries (Layne \& Whitehead, 1985; Malyutina, Bobak, Kurilovitch, Nikitin, \& Marmot, 2004; Power, Rodgers, \& Hope, 1999; Prescott \& Kendler, 2001; Temple, et al., 1991; Zins, Gueguen, Leclerc, \& Goldberg, 2003). However, the effect that remaining unmarried has on alcohol consumption is less clear (Layne \& Whitehead, 1985; Malyutina, et al., 2004; Power, et al., 1999; Prescott \& Kendler, 2001; Temple, et al., 1991; Zins, et al., 2003). It has also been found that much of the short-term harmful alcohol exposure occurs during younger years and that most drinkers reduce their alcohol consumption as they get older (Cryer, et al., 1999; Cryer, et al., 2001). A better understanding of the association between marital status and alcohol consumption among young and middle-aged Australian adults may encourage the development of screening tools which target relatively youthful populations at high-risk for alcohol misuse. The aim of this study was therefore to investigate the association between marital status and alcohol consumption among young and middle-aged Australians (15-45 yrs). 


\section{METHOD}

Details of the survey sampling strategy and data collection methods have been described elsewhere (AIHW, 2008). Briefly, the NDSHS is a National survey targeting the 12+ yrs Australian population. The $2007(n=23,356)$ survey used combinations of the drop-and-collect method and the computer-assisted telephone interview (CATI) method to collect information from household respondents. The survey asked detailed questions about respondent alcohol consumption history in the past 12 months. Additional questions included: marital status, age, sex, income, highest level of education attained and Indigenous status. Survey questionnaires can be obtained from the Australian Institute of Health and Welfare www.aihw.gov.au.

Separate multivariate logistic regression models were first employed to test the hypothesis: Young and middle-aged Australians who are divorced or never married have higher prevalence of harmful alcohol use. Drinkers were defined as respondents who consumed at least one standard drink (drk) of alcohol (10grms pure alcohol) in the 12 months prior to the survey. Alcohol consumption levels were defined according to the 2001 (NHMRC, 2001) and the 2009 NHMRC guidelines (NHMRC, 2007). Long-term risky drinking is defined as: i) 2+ drks/day for women and 4+ drks/day for males (2001 NHMRC); and ii) 2+ drks/day for both men and women (2009 NHMRC). Short-term risky drinking levels were defined as: i) 5+ drks/day for women and 7+ drks/day for males (2001 NHMRC); and ii) 5+ drks/day for both men and women (2009 NHMRC). Age (five-year age groups), gender, state, highest

qualification, income level, indigenous status, and relative advantage/disadvantage of 
residency location (socio-economic indexes for areas (SEIFA) in quartile strata) were adjusted in all models. Further analyses were repeated within each SEIFA quartile.

Respondents aged between 15yrs and 25yrs were excluded in this set of models since a large proportion of the population younger than 25yrs are never-married, and this age group have the highest prevalence of risky drinking (AIHW, 2008). Removing this age group minimised the potential confounding effect of age.

Further analyses were conducted to investigate whether the prevalence of drinking for long-term risk (i.e. chronic harms) was higher in older, never married people than married people from the 15-29yr age group - the latter often pointed to as having the highest prevalence of risky drinking. All models adjusted for age, gender, state, highest qualification, indigenous status and SEIFA. 


\section{RESULTS}

Demographics of the sample have been previously reported in detail in the report: 2007 National Drug Strategy Household Survey: First Results. 2008 (AIHW, 2008). This report can be from the Australian Institute of Health and Welfare www.aihw.gov.au. As shown in Table 1, subjects who were never married, divorced or separated were more likely to regularly consume alcohol at risky levels for longterm harm (NHMRC, 2001, 2009) than those who were married. Respondents who were never married, divorced, or separated also had an increased risk of consuming alcohol at risky levels for short-term harm at least once per month. Interaction effects between marital status and gender were not significant.

When the analyses were repeated for each socio-economic quartile, the association between marital status and alcohol consumption remained with the exception of the second quartile which was not significant.

The likelihood of consuming alcohol at a risky level was compared among four groups defined by both of age (15-29, 30-45) and marital status (married, never married) (Table 2). Being younger and never married was associated with increased likelihood of consuming alcohol at a risky level. Interestingly, never married subjects aged 30-45yrs were more likely to regularly consume alcohol at risky levels for longterm harm, than younger married subjects. 


\section{DISCUSSION}

Data from the 2007 NDSHS was used in this study. The sampling strategy of this national survey ensures that the sample obtained is representative of the Australian population in terms of demographic and socio-economic characteristics (AIHW, 2008).

Our analyses show that among young and middle-aged Australians, people who were never married, divorced or separated were more likely to consume alcohol at risky levels for both long- and short-term harm. The results of this study concur with findings from other population studies (Layne \& Whitehead, 1985; Malyutina, et al., 2004; Power, et al., 1999; Prescott \& Kendler, 2001; Temple, et al., 1991; Zins, et al., 2003) and suggest that marital status is as strong a predictor of risky drinking as is being of a youthful age. Given this, it is feasible that marital status could be used to identify young and middle-aged patients in heath care settings who may be at risk of alcohol-related harms in the short- and long-term.

It is not entirely clear why being married should be associated with a lower likelihood of risky alcohol consumption. Being married has been found be associated with better mental health, physical health and happiness (Lindstrom, 2009; Scott, et al., 2009; Stack \& Eshleman, 1998). It has also been shown that risky alcohol consumption is associated with poor mental health in the Australia population (Burns \& Teesson, 2002; Caldwell, et al., 2002; Rodgers, et al., 2000). It may be possible that mental health status is one of the factors mediating the association between marital status and alcohol consumption. Of particular interest, in this study, divorced or separated subjects had similar levels of risky drinking behaviour to subjects who had never 
married. Again, mental health may be a mediating factor as there is evidence to suggest that divorced or separated individuals are at higher risk of poorer mental health than the married (Afifi, Cox, \& Enns, 2006). In any case, variations in mental health status by marital status is only likely to partly account for the complex mechanisms underlying the associations between marital status and alcohol consumption observed in this study.

\section{$\underline{\text { Limitations }}$}

This study was conducted on an Australian sample, and human behaviours may vary in different countries. The response rate was 49.3\%, however, despite the large national sample attained and the representativeness of the sampling frame, it is not impossible that the participating sample was different from those who refused. This is unfortunately a weakness of all population-based epidemiological studies that require the recruitment of participants. Studies from other nations have shown that people in de facto relationships may have higher rates of risky drinking (Li, Wilsnack, Wilsnack, \& Kristjanson, 2010), however we were unable to separate participants who were legally married from those who were de facto married because of the nature of the dataset. Thus, the variation in drinking behaviours between married and de facto married population could not be ruled out in this study. Nevertheless, the observed association may be partly due to the fact that higher risk for interpersonal problems and social skills deficits were associated with both alcohol use disorders and problematic relationships. 


\section{CONCLUSION}

In this study, we observed that being married was associated with lower prevalence of consuming alcohol at risky levels among young and middle-aged populations. Being never married, divorced or separated was associated with risky alcohol consumption behaviours. The marital status of young and middle-aged people might serve as a useful screening tool for health professionals wishing to identify patients at greatest risk of alcohol-related problems. 


\section{Reference}

Afifi, T. O., Cox, B. J., \& Enns, M. W. (2006). Mental health profiles among married, never-married, and separated/divorced mothers in a nationally representative sample. Soc Psychiatry Psychiatr Epidemiol, 41(2), 122-129.

AIHW. (2008). 2007 National Drug Strategy Household Survey: First Results. Canberra: Australian Institute of Health and Welfare.

Burns, L., \& Teesson, M. (2002). Alcohol use disorders comorbid with anxiety, depression and drug use disorders. Findings from the Australian National Survey of Mental Health and Well Being. Drug Alcohol Depend, 68(3), 299307.

Caldwell, T. M., Rodgers, B., Jorm, A. F., Christensen, H., Jacomb, P. A., Korten, A. E., et al. (2002). Patterns of association between alcohol consumption and symptoms of depression and anxiety in young adults. Addiction, 97(5), 583594.

Cryer, P. C., Jenkins, L. M., Cook, A. C., Ditchburn, J. S., Harris, C. K., Davis, A. R., et al. (1999). The use of acute and preventative medical services by a general population: relationship to alcohol consumption. Addiction, 94(10), 15231532.

Cryer, P. C., Saunders, J., Jenkins, L. M., Neale, H., Cook, A. C., \& Peters, T. J. (2001). Clusters within a general adult population of alcohol abstainers. International Journal of Epidemiology, 30(4), 756-765.

Fillmore, K. M., Kerr, W. C., Stockwell, T., Chikritzhs, T., \& Bostrom, A. (2006). Moderate alcohol use and reduced mortality risk: Systematic error in prospective studies. Addiction Research and Theory, 14, 101-132.

Layne, N., \& Whitehead, P. C. (1985). Employment, marital status and alcohol consumption of young Canadian men. J Stud Alcohol, 46(6), 538-540.

Li, Q., Wilsnack, R., Wilsnack, S., \& Kristjanson, A. (2010). Cohabitation, Gender, and Alcohol Consumption in 19 Countries: A Multilevel Analysis. Subst Use Misuse.

Lindstrom, M. (2009). Marital status, social capital, material conditions and self-rated health: a population-based study. Health Policy, 93(2-3), 172-179.

Malyutina, S., Bobak, M., Kurilovitch, S., Nikitin, Y., \& Marmot, M. (2004). Trends in alcohol intake by education and marital status in urban population in Russia between the mid 1980s and the mid 1990s. Alcohol Alcohol, 39(1), 64-69.

NHMRC. (2001). Australian Alcohol Guidelines: Health Risks and Benefits: Australian National Health and Medical Research Council.

NHMRC. (2007). Australian alcohol guidelines for low-risk drinking: Australian National Health and Medical Research Council.

NHMRC. (2009). Australian guidelines to reduce health risks from drinking alcohol: Australian National Health and Medical Research Council.

Power, C., Rodgers, B., \& Hope, S. (1999). Heavy alcohol consumption and marital status: disentangling the relationship in a national study of young adults. Addiction, 94(10), 1477-1487.

Prescott, C. A., \& Kendler, K. S. (2001). Associations between marital status and alcohol consumption in a longitudinal study of female twins. J Stud Alcohol, 62(5), 589-604. 
Rodgers, B., Korten, A. E., Jorm, A. F., Jacomb, P. A., Christensen, H., \& Henderson, A. S. (2000). Non-linear relationships in associations of depression and anxiety with alcohol use. Psychol Med, 30(2), 421-432.

Scott, K. M., Wells, J. E., Angermeyer, M., Brugha, T. S., Bromet, E., Demyttenaere, K., et al. (2009). Gender and the relationship between marital status and first onset of mood, anxiety and substance use disorders. Psychol Med, 1-11.

Stack, S., \& Eshleman, J. R. (1998). Marital Status and Happiness: A 17-Nation Study. Journal of Marriage and Family, 60(2), 527-536.

Temple, M. T., Fillmore, K. M., Hartka, E., Johnstone, B., Leino, E. V., \& Motoyoshi, M. (1991). A meta-analysis of change in marital and employment status as predictors of alcohol consumption on a typical occasion. $\mathrm{Br} J$ Addict, 86(10), 1269-1281.

WHO. (2000). International Guide for Monitoring Alcohol Consumption and Related Harm: World Health Organization.

Wilkins, R., Warren, D., \& Hahn, M. (2009). Families, Incomes and Jobs, Volume 4: A Statistical Report on Waves 1 to 6 of the HILDA Survey Melbourne: Melbourne Institute of Applied Economic and Social Research.

Zins, M., Gueguen, A., Leclerc, A., \& Goldberg, M. (2003). Alcohol consumption and marital status of French women in the GAZEL cohort: a longitudinal analysis between 1992 and 1996. J Stud Alcohol, 64(6), 784-789. 
Table 1 Marital status and alcohol consumption behaviours

\begin{tabular}{|c|c|c|c|c|c|c|}
\hline \multirow{4}{*}{ Total sample } & \multicolumn{3}{|c|}{$\begin{array}{l}\text { NHMRC } 09 \text { long-term risk (0: low } \\
\text { risk, 1: risky) }\end{array}$} & \multicolumn{3}{|c|}{$\begin{array}{l}\text { NHMRC } 09 \text { short-term risk at least } \\
\text { monthly (0: low risk, } 1 \text { : risky ) }\end{array}$} \\
\hline & \multirow{3}{*}{$\begin{array}{l}\text { Odds } \\
\text { Ratio }\end{array}$} & \multirow{2}{*}{\multicolumn{2}{|c|}{$\begin{array}{l}95 \% \text { confidence } \\
\text { interval }\end{array}$}} & \multirow{3}{*}{$\begin{array}{l}\text { Odds } \\
\text { Ratio }\end{array}$} & \multirow{2}{*}{\multicolumn{2}{|c|}{$\begin{array}{l}95 \% \text { confidence } \\
\text { interval }\end{array}$}} \\
\hline & & & & & & \\
\hline & & & & & & \\
\hline married or de facto & 1.00 & & & 1.00 & & \\
\hline never married & $1.86 *$ & 1.49 & 2.31 & $2.08 *$ & 1.72 & 2.51 \\
\hline divorced or separated & $1.71 *$ & 1.23 & 2.40 & $1.92 *$ & 1.45 & 2.56 \\
\hline \multicolumn{7}{|c|}{ Subgroup: SEIFA 1 (least advantage) } \\
\hline married or de facto & 1.00 & & & & & \\
\hline never married & $1.86 *$ & 1.12 & 3.09 & $1.77 *$ & 1.15 & 2.73 \\
\hline divorced or separated & $2.62 *$ & 1.23 & 5.55 & $3.19 *$ & 1.70 & 5.98 \\
\hline \multicolumn{7}{|l|}{ Subgroup: SEIFA 2} \\
\hline married or de facto & 1.00 & & & 1.00 & & \\
\hline never married & 1.04 & 0.59 & 1.81 & 1.30 & 0.83 & 2.04 \\
\hline divorced or separated & 1.53 & 0.73 & 3.24 & 1.35 & 0.72 & 2.51 \\
\hline \multicolumn{7}{|l|}{ Subgroup: SEIFA 3} \\
\hline married or de facto & 1.00 & & & 1.00 & & \\
\hline never married & $2.68 *$ & 1.77 & 4.06 & $2.76^{*}$ & 1.91 & 3.99 \\
\hline divorced or separated & $2.08 *$ & 1.11 & 3.89 & $1.84 *$ & 1.07 & 3.15 \\
\hline \multicolumn{7}{|c|}{ Subgroup: SEIFA 4 (most advantage) } \\
\hline married or de facto & 1.00 & & & 1.00 & & \\
\hline never married & $1.93 *$ & 1.32 & 2.81 & $2.28 *$ & 1.64 & 3.17 \\
\hline \multirow[t]{2}{*}{ divorced or separated } & 1.27 & 0.68 & 2.35 & $1.88 *$ & 1.10 & 3.22 \\
\hline & \multicolumn{3}{|c|}{$\begin{array}{l}\text { NHMRC } 01 \text { long-term risk (0: low } \\
\text { risk, 1: risky) }\end{array}$} & \multicolumn{3}{|c|}{$\begin{array}{l}\text { NHMRC } 01 \text { short-term risk at least } \\
\text { monthly ( } 0 \text { : low risk, } 1 \text { : risky) }\end{array}$} \\
\hline \multicolumn{7}{|l|}{ total sample } \\
\hline married or de facto & 1.00 & & & 1.00 & & \\
\hline never married & $2.16^{*}$ & 1.69 & 2.76 & $2.12^{*}$ & 1.75 & 2.56 \\
\hline divorced or separated & $1.66^{*}$ & 1.15 & 2.39 & $2.17 *$ & 1.64 & 2.87 \\
\hline \multicolumn{7}{|c|}{ Subgroup: SEIFA 1 (least advantage) } \\
\hline married or de facto & 1.00 & & & 1.00 & & \\
\hline never married & $2.04 *$ & 1.20 & 3.49 & $1.77^{*}$ & 1.15 & 2.73 \\
\hline divorced or separated & 1.85 & 0.85 & 4.00 & $3.12 *$ & 1.69 & 5.76 \\
\hline \multicolumn{7}{|l|}{ Subgroup: SEIFA 2} \\
\hline married or de facto & 1.00 & & & 1.00 & & \\
\hline never married & 1.24 & 0.65 & 2.34 & 1.49 & 0.95 & 2.33 \\
\hline divorced or separated & 1.70 & 0.76 & 3.83 & 1.38 & 0.73 & 2.62 \\
\hline \multicolumn{7}{|l|}{ Subgroup: SEIFA 3} \\
\hline married or de facto & 1.00 & & & 1.00 & & \\
\hline never married & $2.22 *$ & 1.39 & 3.55 & $2.93 *$ & 2.04 & 4.22 \\
\hline divorced or separated & 1.67 & 0.84 & 3.31 & $2.65 *$ & 1.56 & 4.52 \\
\hline \multicolumn{7}{|c|}{ Subgroup: SEIFA 4 (most advantage) } \\
\hline married or de facto & 1.00 & & & 1.00 & & \\
\hline never married & $2.83 *$ & 1.83 & 4.39 & $2.19 *$ & 1.58 & 3.04 \\
\hline divorced or separated & 1.64 & 0.79 & 3.39 & $2.07 *$ & 1.22 & 3.52 \\
\hline
\end{tabular}




\section{Table 2 Age, Marital status and alcohol consumption behaviours}

\begin{tabular}{|c|c|c|c|c|c|c|}
\hline & \multicolumn{3}{|c|}{$\begin{array}{l}\text { NHMRC } 09 \text { long term risk (0: low } \\
\text { risk, 1: risky) }\end{array}$} & \multicolumn{3}{|c|}{$\begin{array}{l}\text { NHMRC } 09 \text { short term risk at least } \\
\text { monthly ( } 0 \text { : low risk, } 1 \text { : risky) }\end{array}$} \\
\hline & Odds & {$[95 \%$} & Interval] & Odds & {$[95 \%$} & Interval] \\
\hline & Ratio & Conf. & & Ratio & Conf. & \\
\hline 15-29 married & 1.00 & & & 1.00 & & \\
\hline 30-45 never married & 1.27 & 1.00 & 1.61 & 0.85 & 0.70 & 1.04 \\
\hline 15-29 never married & $1.37 *$ & 1.13 & 1.67 & $1.37 *$ & 1.17 & 1.61 \\
\hline \multirow[t]{2}{*}{ 30-45 married } & 0.84 & 0.70 & 1.02 & $0.52 *$ & 0.45 & 0.61 \\
\hline & \multicolumn{3}{|c|}{$\begin{array}{l}\text { NHMRC } 01 \text { long term risk (0: low } \\
\text { risk, 1: risky) }\end{array}$} & \multicolumn{3}{|c|}{$\begin{array}{l}\text { NHMRC } 01 \text { short term risk at least } \\
\text { monthly ( } 0 \text { : low risk, } 1 \text { : risky) }\end{array}$} \\
\hline 15-29 married & 1.00 & & & 1.00 & & \\
\hline 30-45 never married & $1.52 *$ & 1.16 & 1.99 & 0.90 & 0.73 & 1.09 \\
\hline 15-29 never married & $1.76 *$ & 1.41 & 2.20 & $1.61 *$ & 1.38 & 1.89 \\
\hline 30-45 married & 0.96 & 0.78 & 1.20 & $0.53 *$ & 0.45 & 0.62 \\
\hline
\end{tabular}

